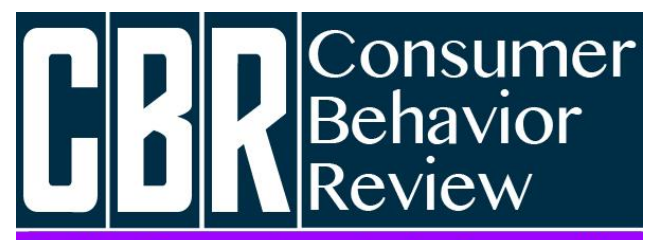

Revista Comportamento do Consumidor
Castro, A. L. O., Vilas Boas, L. H. B., Rezende, D. C., \& Pimenta, M. L. (2021). Os Traços Identitários dos Consumidores de Vinhos em Minas Gerais. Consumer Behavior Review, 5(2), 243-260.
ISSN: 2526-7884

Editor: Prof. Dr. Marconi Freitas da Costa

E-mail: cbr@ufpe.br
Avaliação: Double blind review

Recebido: 14 de Outubro, 2020

Aceito: 13 de Abril, 2021

\title{
OS TRAÇOS IDENTITÁRIOS DOS CONSUMIDORES DE VINHOS EM MINAS GERAIS
}

The Identity Traits of Wine Consumers in Minas Gerais

Álvaro Leonel de Oliveira Castro ${ }^{1}$

ORCID: http://orcid.org/0000-0002-2779-6745

E-mail: alvaroleonel@outlook.com

Luiz Henrique de Barros Vilas Boas ${ }^{1}$

ORCID: http://orcid.org/0000-0002-6429-1420

E-mail: luiz.vilasboas@ufla.br

Daniel Carvalho de Rezende ${ }^{1}$

ORCID: http://orcid.org/0000-0003-1277-724X

E-mail: danielderezende@ufla.br

Márcio Lopes Pimenta²

ORCID: http://orcid.org/0000-0003-3899-3274

E-mail: pimenta@ufu.br

${ }^{1}$ Universidade Federal de Lavras, Lavras, Minas Gerais, Brasil

${ }^{2}$ Universidade Federal de Uberlândia, Uberlândia, Minas Gerais, Brasil

\begin{abstract}
Resumo
O vinho se faz presente em vários períodos da história da humanidade e a sua representação simbólica, cultural e social, demonstra-se pertinente para que as pessoas desenvolvam traços identitários em razão do consumo da bebida. Este artigo teve como objetivo identificar e descrever os traços identitários dos consumidores de vinhos em Minas Gerais, com base nos princípios de identidade baseada em motivação (saliência, associação,
\end{abstract}

\begin{abstract}
Wine is present in various periods in the history of mankind and its symbolic, cultural and social representation proves to be relevant for people to develop identity traits due to the consumption of the drink. This article aimed to identify and describe the identity traits of wine consumers in Minas Gerais, based on the principles of identity based on motivation (salience, association, relevance, verification and conflict) by Reed et
\end{abstract}


relevância, verificação e conflito) de Reed et al. (2012). Para isto, realizou-se 40 entrevistas com consumidores assíduos da bebida em quatro cidades do estado de Minas Gerais. Os resultados indicam que a saliência identitária decorre da afirmação das características únicas que moldam suas atitudes e reforçam esta percepção. A associação acontece ao resgatar memórias de locais visitados e lembranças pessoais, bem como vincular o consumo a outras atividades ou pessoas. A relevância ocorre conforme as avaliações de suas ações mediante ao objetivo do consumo, além dos aspectos simbólicos envolvidos. A verificação leva em consideração a validação da identidade ao cumprir normas estabelecidas. 0 conflito ocorre quando múltiplas identidades atuam em mesmo contexto de consumo. Conclui-se que o consumo de vinhos é uma atividade capaz de formar traços identitários nos consumidores, aumentando o engajamento com a bebida.

Palavras-chave: Consumo de vinhos; Traços identitários; Minas Gerais. al. (2012). Forty interviews were conducted with regular consumers of the drink in four cities in Minas Gerais. The results indicate that the identitary salience stems from the affirmation of the unique characteristics that shape their attitudes and reinforce this perception. The association takes place by retrieving memories of visited places and personal memories, as well as linking consumption to other activities or people. Relevance occurs according to the assessments of your actions based on the objective of consumption, in addition to the symbolic aspects involved. Verification takes into account identity validation when meeting established standards. The conflict occurs when multiple identities operate in the same context of consumption. It is concluded that wine consumption is an activity capable of forming identity traits in consumers, increasing engagement with the drink.

Keywords: Wine consumption; Identity traits; Minas Gerais.

\section{INTRODUÇÃO}

A indústria de vinhos de acordo com Banks e Overton (2010), pode ser caracterizada pela sua capacidade de mediar processos complexos, frente à expressiva globalização que se passa no setor vitivinícola. Para Berríos e Saens (2015), o setor é constantemente influenciado por seus produtores, sejam eles pequenos e conservadores cultivadores de uvas artesanais no Velho Mundo (delimitado no continente europeu), ou pelos fabricantes em larga escala da bebida, alocados no Novo Mundo (EUA, Austrália, África, Oriente Médio e América do Sul).

Mesmo caracterizando-se enquanto uma bebida milenar, o vinho tem cada vez mais se demonstrado um produto com um alto potencial de mercado, sobretudo, quando se fala na produção da bebida no Brasil. Neste sentido, a vitivinicultura brasileira é representada a nível nacional com grande destaque para o sul do país, conforme afirmam Protas e Camargo (2011). Para estes autores, na produção de vinhos brasileira destaca-se o estado do Rio Grande do Sul, o qual prevalece as regiões da Serra Gaúcha, Campanha, Serra do Sudeste e a região central.

Quanto a produção de vinhos, Mello (2017) enfatiza que os números do estado gaúcho podem ser inferidos para a manufatura total brasileira, uma vez que $90 \%$ da fabricação de vinhos está concentrada na região sulista rio-grandense, de modo que a área cultivada com videiras representa cerca de 77.786 hectares. 0 Instituto Brasileiro do Vinho ressalta que a diversidade climática do país e o investimento em inovação, tem resultado em vinhos de rótulos típicos, que levam à personalidade $\mathrm{e}$ a cultura brasileira para o exterior (Ibravin, 2018).

Visando estimular o consumo de vinho no Brasil, é importante compreender os aspectos que motivam o consumo da bebida. Uma possibilidade de investigação empírica acerca do comportamento de consumo, tendo o vinho quanto objeto de estudo, são as questões relacionadas aos traços de identidade que permeiam a personalidade dos consumidores. 0 vinho está presente em vários períodos da história da humanidade, de modo que a sua representação simbólica, cultural e social, demonstra-se manifesta até hoje nos tempos contemporâneos. Então, as pessoas que adotam a bebida 
em seus estilos de vida e em seu convívio social, são passíveis de desenvolverem perfis identitários em razão da forte relação que o produto possui em contextos de consumo e estilos de vida, tais como jantares, reuniões de apreciação e degustação em grupos especializados, comemorações e confraternizações.

Nesta perspectiva, o vinho tem sido objeto de estudo em identidade pelos pesquisadores, os quais investigaram o envolvimento e o autoconceito em contextos situacionais com a bebida (Roe \& Bruwer, 2017); o "coorte" etário e a sociodemografia entre idosos e jovens, em que as compras de vinhos especiais aumentam em razão do envelhecimento do indivíduo (Bruwer \& McCutcheon, 2017); a formação identitária de consumidores em face a influência de atributos como a marca, altos preços, ponto de venda (não)tradicional, gostos, categoria de luxo e local de origem (Higgins \& Wolf, 2016; Spielmann et al., 2016); e a influência do estilo de vida e dos contatos socioculturais, mediante ao forte envolvimento com o vinho na construção da identidade do consumidor (Rössel \& Pape, 2016; Ritchie, 2007).

Para Reed II et al (2012), as pessoas desenvolvem a identidade de acordo com as suas escolhas, aderindo a rótulos identitários conforme a sua vontade ou sendo induzidas pelo contexto em que o consumo acontece, representando de forma clara a autoimagem do indivíduo. Os autores situam cinco princípios de identidade (saliência, associação, relevância, verificação e conflito) no comportamento de consumo, os quais podem descrever os traços identitários destes consumidores mediantes às motivações de consumo. Então, este artigo teve como objetivo identificar e descrever os traços de identidade dos consumidores de vinhos, com base nos princípios de identidade baseada em motivação no comportamento de consumo. 0 estudo se justifica no que se refere ao contexto brasileiro, de modo que obter informações sobre o consumo de vinhos e os aspectos ligados à identidade destes consumidores, pode estimular a produção, a distribuição e a comercialização do produto, aumentando a representatividade e a disseminação do consumo de vinhos entre os consumidores do Brasil (Carvalho, 2016).

\section{A FORMAÇÃO DE IDENTIDADE NA ESFERA DO COMPORTAMENTO DE CONSUMO}

O conceito de identidade foi discutido ao longo do tempo, e tem sido alvo de debate até os dias atuais. No resgate teórico de Kassarjian (1971), os primórdios da discussão acerca do conceito de identidade no início do século XX, tem sua base fundamentada em várias teorias ligadas à psicanálise, ao contexto social, a aprendizagem, aos traços e fatores de personalidade, e ao estilo de vida de uma pessoa. Desde então, sobretudo a partir da década de 1980, o conceito de identidade tem sido recorrentemente pesquisado em diversos campos de conhecimento das ciências sociais, tais como a antropologia, sociologia e psicologia (Souza \& Carrieri, 2012).

No âmbito das ciências sociais aplicadas, de acordo com Souza e Carrieri (2012), o conceito de identidade tem sido estudado em administração sob a ótica da perspectiva social e individual de uma pessoa. Para Dubar (2012), a definição de identidade envolve as noções que o indivíduo tem de si, em um caráter pessoal ou coletivo, objetivo ou subjetivo, estável ou provisório, que compõem a biografia e a estrutura do sujeito, sendo resultado da constante construção de sua personalidade conforme o decorrer de sua vida em sociedade.

Na vertente do marketing, o conceito de identidade é visto como central para a noção de quem o indivíduo é, perante a si e a sociedade em sua volta. Sob a perspectiva do consumo, a definição de identidade abrange os bens e experiências que uma pessoa possui ou não gostaria de possuir, em função dos significados simbólicos que eles carregam. Estas avaliações e definições de si mesmo, influem diretamente nas ações de consumo, tais como aquisições de produtos ou serviços que tenham congruência direta com a imagem que o consumidor queira passar de si, conforme a sua personalidade, cultura e crenças (Barbosa \& Campbell, 2006). Belk (2014) enfatiza que o contexto cultural e social pode influenciar na forma pelas quais os indivíduos apresentam as suas identidades em situações de consumo.

A sociedade contemporânea a partir do século XX tem reconfigurado muitos parâmetros estabelecidos como centrais na concepção humana, no que se refere as questões de classes sociais, gênero, sexualidade, cultura, etnia, nacionalidade, entre outros fatores (Hall, 2006). Tais mudanças 
caracterizam a noção de identidade na pós-modernidade, em que os eventos contemporâneos deste mundo globalizado, transformou e fragmentou a forma em que as pessoas identificam a si mesmas. Logo, Hall (2006) diz que a concepção de uma identidade unificada, completa, autêntica, coerente e segura, não condiz com a representação de um indivíduo em tempos que a noção identitária tem sido descentralizada. Então, as tensões do sujeito pós-moderno fazem com que ele reformule sua identidade de forma continua. Nesse sentido, Udall et al. (2020) descreve que a identidade é utilizada como uma referência que ajuda a orientar comportamentos de consumo, e dependendo das situações que são vivenciadas pelos consumidores, um traço identitário pode estar prontamente acessível em relação aos outros.

Clair (2018) argumenta que em termos de consumo, os indivíduos detêm diversos traços de identidade que podem influenciar no comportamento de consumo, e, dessa forma, é inevitável que estas múltiplas identidades em constante transformação entrem em conflito. Nesse sentido, o consumo pode ampliar (Bauman, 2005) ou solucionar (Barbosa \& Campbell, 2006) estas tensões identitárias. Para Bauman (2005), a relação entre o consumo e identidade tem fundamento na busca incansável por produtos e experiências, que resultam em danos na noção da ética social e ambiental entre os humanos. Já na visão de Barbosa e Campbell (2006), o consumo na pós-modernidade trata-se de um processo social, que ajuda as pessoas produzirem sentido e formarem as suas identidades pessoais no que tange ao seu estilo de vida, personalidade, valores e motivações, sendo então, um meio para se sanar as crises de identidade.

Embasando-se na motivação como meio de construção identitária, Oyserman (2009) posiciona o conceito de identidade como altamente maleável e sensível às situações que são experimentadas por uma pessoa em um grupo social. Ou seja, as atitudes, escolhas e comportamentos que são repetidamente vivenciadas nas relações familiares, profissionais, afetivas, emocionais e sociais por uma pessoa ao longo do tempo, influenciam diretamente na construção da identidade do indivíduo frente a sociedade (Oyserman et al., 2012). Com base nesta abordagem, considera-se que uma identidade pode ser moldada mediante às situações psicologicamente isomórficas, ou seja, de forma dinâmica e em conformidade com o ambiente em que se está inserido, implicando nas ações e na interpretação das situações expostas.

Para Reed II et al. (2012), esta perspectiva representou o primeiro passo para agrupar as vertentes dos estudos identitários ao redor do conceito de motivação. 0 trabalho de Oyserman (2009) trouxe contribuições para as pesquisas de comportamento de consumo e identidade, ao afirmar que os consumidores tendem a fazer escolhas mais congruentes com sua motivação e compatíveis com a sua identidade, observando as implicações do consumo para si e para o grupo em que está inserido. Com base nas conclusões de Oyserman (2009) acerca da identidade baseada na motivação e em uma extensa revisão de literatura, Reed II et al. (2012) elaboraram cinco princípios de identidade ligados ao comportamento de consumo, que ajudam entender como a motivação e outros fatores relacionados moldam a identidade do consumidor:

Saliência: delimita os traços que formam a identidade dos consumidores. Com base neste princípio, um indivíduo pode afirmar veementemente a noção de quem é, ou seja, a percepção de sua identidade. Os consumidores consideram possuir características que o tornam único, se comparado a outras pessoas que fazem parte de seu convívio social. Influencias externas de grupos relacionados podem moldar ou reforçar a saliência.

Associação: se manifesta na identidade do consumidor, quando lembranças e memórias retomadas, orientam a percepção de quem o indivíduo é. Neste sentido, a associação de momentos marcantes na vida do consumidor, ou ainda, locais que ele tenha como uma referência de um modo de vida, são meios de se entender este princípio. A transferência associativa também pode ser considerada uma via que edifica a identidade do indivíduo.

Relevância: a formação de identidade pode ser compreendida por meio de cinco aspectos que motivam o consumo: o objeto em si, o simbolismo do consumo, o objetivo do consumo, a ação em si, e a avaliação da identidade quando já está consolidada. 
Verificação: é uma forma do consumidor monitorar a fidelidade de sua identidade, em razão da imagem que se quer passar em um contexto de consumo. Neste sentido, busca-se verificar e validar a noção de quem o consumidor julga ser, perante o ambiente em que se está inserido. Nas situações em que o indivíduo aspire por novas identidades, ele se comporta de uma forma que o posicione como o "eu ideal" pretendido.

Conflito: é algo inevitável, uma vez que são várias as pessoas que compõem um meio social, e, neste sentido, deve-se adotar alguns processos autorregulatórios, que gerem uma postura harmônica diante destas múltiplas identidades.

Reed II et al. (2012) dizem que estes princípios se aplicam aos rótulos de categorias que constituem uma identidade em qualquer contexto, sendo um ponto de partida útil ao examinar pontualmente os aspectos que fazem uma identidade de consumo ser relevante, promovendo importantes reflexões nas pesquisas em marketing e comportamento de consumo. Por fim, os autores afirmam que estes princípios, tem o foco direcionado à compreensão sobre os meios pelos quais as pessoas respondem ao mundo externo de acordo com as suas identidades, possibilitando o apontamento de tendências emergentes no mercado e no consumo.

\section{Estudos de formação de identidade no contexto de consumo de vinhos}

0 vinho é dotado de significados simbólicos, culturais e sociais, e se faz presente em inúmeros contextos que contam a história da humanidade. Assim, é inegável a importância que esta bebida assume enquanto um objeto de estudo, sobretudo, quando investigado na ótica do marketing e comportamento do consumidor. Isto posto, vários contextos (confrarias, jantares harmonizados, confraternizações, consumo ocasional, etc.) podem retratar diferentes traços de identidade, de modo que estas situações de consumo demonstram-se pertinentes para se compreender este fenômeno. Neste sentido, os parágrafos seguintes trazem uma breve revisão de literatura de estudos empíricos que investigaram como se dá a formação de identidade no consumo de vinhos, em diferentes situações e contextos de consumo. Além disto, estes podem contribuir com a discussão a ser realizada neste artigo, em face aos resultados encontrados.

Ritchie (2007) menciona que o consumo social do vinho tornou-se parte da identidade e do estilo de vida de muitos apreciadores da bebida, e muda significativamente conforme a ocasião e o ambiente em que o produto é consumido. Neste contexto, a autora realizou grupos focais com consumidores assíduos, e identificou que há uma variedade de comportamentos em interações sociais que estão sujeitas à situação de consumo, tais como presentear uma pessoa, participar de um jantar ou apreciar a bebida, as quais dependem se a atividade é percebida enquanto pública ou privada, pois estas influenciam na decisão de qual vinho será comprado. Ressalta-se que quando o produto é incorporado ao comportamento cultural e aos aspectos de interação social, diferentes identidades podem emergir conforme o contexto de consumo.

O estudo realizado por Bruwer e Li (2007), identificou cinco perfis de identidade de consumidores baseando-se em seus estilos de vida. Os grupos identitários podem ser caracterizados em: conservadores e conhecedores, os quais estão na meia idade, possuem alta remuneração e nível de educação, e bebem vinho finos com frequência, havendo interesse em sua procedência, canal de compra e ocasião de consumo; os bebedores sociais, que representam um público mais jovem que consomem o produto em companhia de amigos nos finais de semana, e levam em consideração a marca, sofisticação e experiência de consumo; os bebedores básicos, os quais apenas prezam pelo sabor do produto, não havendo rituais de consumo e maiores exigências quanto a escolha; os apreciadores aposentados, os quais possuem idade avançada e sempre demonstraram interesse no produto, e utilizam seu tempo disponível para aprender, conhecer e experimentar vinhos finos; e os novos profissionais, que possuem pequenas adegas em suas casas ou escritórios, para oferecer o vinho em ocasiões que envolvam atividades comerciais, visando criar entretenimento e informalidade durante as negociações. 
Rössel e Pape (2016) investigaram a relevância dos estilos de vida, contatos sociais e posição socioeconômica, em face à identidade de consumo de vinhos. Os respondentes que indicaram uma estreita relação com produtos vitivinícolas, tendem a possuir um estilo de vida de alto padrão social e demandam mais pela bebida, os quais sofrem influências mediante à idade, gênero e região de residência. Entretanto, a posição socioeconômica e os contatos sociais não são determinantes para gerar identidade no consumo de vinhos, e sim, o estilo de vida e contextos sociais específicos. Quanto a uma parcela que não assumiu vínculo identitário com a bebida em questão, os autores consideram que a democratização e o maior acesso ao vinho, fez com que muitas pessoas acreditassem que o consumo do produto em ocasiões eventuais, não seja relevante para a construir e manter uma identidade específica.

Um segmento emergente no consumo de vinhos é a geração formada por millennials, ou seja, jovens consumidores nascidos em um contexto de vida ligado às inovações tecnológicas e digitais. Nesse sentido, o trabalho de Higgins e Wolf (2016) caracterizam que estes novos consumidores, atrelam o consumo de vinhos aos seus estilos de vidas e ao hedonismo em sua personalidade, porém, a sua renda financeira é determinante para o consumo da bebida. Outro achado importante destas autoras, é que os millennials são um público que buscam informação sobre o produto, incluindo, plataformas digitais e redes sociais, para trocar experiências com a sua rede de contatos que possuem relação com o mundo dos vinhos. Também considerando este grupo social, Spielmann, Babin e Verghote (2016) avaliaram as motivações de consumo mediante a identidade dos consumidores millennials. A pesquisa apontou que estes indivíduos se concentram na sua autopercepção enquanto indivíduos sociais, de modo que a dimensão social da personalidade do vinho é congruente com a autoimagem que eles desejam afirmar em seu contexto de vida, posicionando-se como intelectuais, experientes e conhecedores da filosofia de consumo da bebida, sobretudo, quando os vinhos estão associados ao Velho Mundo.

Roe e Bruwer (2017) examinaram a relação entre a identidade dos consumidores conforme o nível de envolvimento com o vinho, mediante as decisões de compra para consumo em ocasiões de socialização. De acordo com o estudo, os consumidores de baixo envolvimento estão mais inclinados a comprar vinhos finos e caros, com o intuito de afirmar a sua identidade em um grupo de pessoas já estabelecidas na degustação do produto, visando à aprovação perante a opinião social, ou ainda, se sentir especial e único no ambiente. Estes consumidores buscam conhecimento especializado sobre vinhos, e ficam preocupados caso ofereçam um produto inadequado, de modo que esta má escolha reflita na percepção do grupo sobre si. No que se refere aos consumidores de maior envolvimento, eles geralmente possuem idade mais avançada e não se atentam quanto à opinião social, uma vez que já estão consolidados no grupo.

\section{PROCEDIMENTOS METODOLÓGICOS}

Com o objetivo de identificar e descrever os traços de identidade no comportamento de consumo de vinhos, com base nos princípios de identidade baseada em motivação no comportamento de consumo, foram feitas 40 entrevistas com consumidores assíduos da bebida. As entrevistas ocorreram nos municípios mineiros de Belo Horizonte, Lavras, Uberlândia e Varginha, no último trimestre de 2018. Os entrevistados foram contatados por meio de distribuidoras, lojas especializadas, restaurantes, confrarias, clubes, entre outros grupos ou estabelecimentos, que caracterizam-se enquanto meios adequados para se conseguir contato com público alvo. Também utilizou-se do critério de conveniência e a técnica de bola de neve para prospectar os sujeitos de pesquisa. 0 Quadro 1 apresenta uma síntese do perfil sociodemográfico dos consumidores entrevistados.

\begin{tabular}{|l|lll|}
\hline Sexo & Masculino (72\%) & Feminino (28\%) & \\
\hline Idade & $\begin{array}{l}\text { 18 a 27 anos (3\%) } \\
\text { 48 a 57 anos (23\%) }\end{array}$ & $\begin{array}{l}\text { 28 a 37 anos (15\%) } \\
\text { 57 a 67 anos (18\%) }\end{array}$ & $\underline{\mathbf{3 8} \text { a 47 anos (36\%) }}$ \\
& & & \\
\hline $\begin{array}{l}\text { Acima de 61 anos (5\%) } \\
\text { familiar }\end{array}$ & $\begin{array}{l}\text { Entre 1 a 3 salários (5\%) } \\
\text { Entre 10 e 12 salários }\end{array}$ & $\begin{array}{l}\text { Entre 4 e 6 salários (8\%) } \\
\text { Entre 13 e 15 salários }\end{array}$ & $\begin{array}{l}\text { Entre 7 e 9 salários (8\%) } \\
\text { Entre 16 e 18 salários }\end{array}$ \\
\hline
\end{tabular}




\begin{tabular}{|l|lll|}
\hline & $\begin{array}{l}\mathbf{( 2 0 \% )} \\
\text { Entre 19 e 21 salários } \\
(10 \%)\end{array}$ & $\begin{array}{l}(8 \%) \\
\text { Entre 22 e 24 salários } \\
(3 \%)\end{array}$ & $\begin{array}{l}\mathbf{( 1 8 \% )} \\
\underline{\text { Acima de 25 salários }} \\
\mathbf{( 2 0 \% )}\end{array}$ \\
\hline Estado Civil & Solteiro(a) (18\%) & $\underline{\text { Casado(a) } \mathbf{6 9 \% )}}$ & Divorciado(a) (13\%) \\
\hline Escolaridade & $\begin{array}{l}\text { Ensino médio (5\%) } \\
\text { Pós-graduação (70\%) }\end{array}$ & $\begin{array}{l}\text { Superior incompleto } \\
(10 \%)\end{array}$ & Superior completo (15\%) \\
& & & \\
\hline
\end{tabular}

Fonte: Dados da pesquisa

Quadro 1. Perfil sociodemográfico considerando o total de 40 entrevistados no estudo

Com o intuito de verificar se os sujeitos de pesquisa possuíam envolvimento com o consumo de vinhos, aplicou-se um breve formulário antes de iniciar-se a entrevista para conhecer o perfil de consumo da bebida entre os participantes. Quanto a caracterização dos entrevistados, estes possuem uma forte relação com o consumo de vinhos especiais, e enquadram-se nos seguintes critérios: consomem a bebida regularmente, em uma periodicidade inferior a um ciclo semanal; investem recursos financeiros para adquirir vinhos especiais mensalmente; participam de confrarias, clubes, jantares, viagens, reuniões e/ou encontros que tenham o objetivo de apreciar, discutir e/ou harmonizar a bebida com alimentos apropriados. 0 Quadro 2 faz o detalhamento do perfil de consumo de vinhos que foi identificado em meio aos entrevistados.

\begin{tabular}{|c|c|c|c|}
\hline $\begin{array}{l}\text { Consumo por } \\
\text { semana }\end{array}$ & De 1 a 2 vezes (31\%) & $\begin{array}{l}\text { De } 3 \text { a } 4 \text { vezes }(31 \%) \\
\text { Acima de } 7 \text { vezes (5\%) }\end{array}$ & De 5 a 6 vezes $(33 \%)$ \\
\hline $\begin{array}{l}\text { Última } \\
\text { compra }\end{array}$ & Há menos de 1 mês (93\%) & De 1 a 3 meses (5\%) & De 3 a 6 meses (2\%) \\
\hline Canal* & Lojas especializadas (57\%) & $\begin{array}{l}\text { Sites especializados } \\
(51 \%)\end{array}$ & Supermercados (28\%) \\
\hline $\begin{array}{l}\text { Preferência } \\
\text { de consumo* }\end{array}$ & $\begin{array}{l}\text { Tintos }(95 \%) \\
\text { Rosés }(28 \%)\end{array}$ & $\begin{array}{l}\text { Brancos }(46 \%) \\
\text { De sobremesa }(12 \%)\end{array}$ & $\begin{array}{l}\text { Espumantes (41\%) } \\
\text { Licorosos (5\%) }\end{array}$ \\
\hline $\begin{array}{l}\text { Atividades } \\
\text { relacionadas* }\end{array}$ & $\begin{array}{l}\text { Jantar harmonizado }(87 \%) \\
\text { Confrarias }(66 \%) \\
\text { Cursos e treinamentos } \\
(46 \%)\end{array}$ & $\begin{array}{l}\text { Presentar pessoas }(84 \%) \\
\text { Seguir redes sociais } \\
(51 \%) \\
\text { Avaliar vinhos }(36 \%)\end{array}$ & $\begin{array}{l}\text { Enoturismo }(74 \%) \\
\text { Clubes de assinatura } \\
(49 \%) \\
\text { Assinar revistas }(23 \%) \\
\end{array}$ \\
\hline Posses* & Adega própria (84\%) & Taças apropriadas (77\%) & $\begin{array}{l}\text { Coolers refrigerados } \\
(41 \%)\end{array}$ \\
\hline
\end{tabular}

Fonte: Dados da pesquisa.

Quadro 2. Perfil de consumo de vinhos considerando o total de 40 entrevistados no estudo

Enquanto técnica de coleta de dados, foram feitas entrevistas em profundidade. Assim, utilizou-se de um roteiro de entrevistas semiestruturado, observando as recomendações de Stewart e Cash Jr. (2015). Foram feitas perguntas primárias para conhecer um pouco mais sobre o contexto de consumo de vinhos na visão do entrevistado, perguntas de sondagem para compreender como se dá o envolvimento do entrevistado com o consumo de vinhos no âmbito pessoal e social, e perguntas direcionadas que foram elaboradas conforme os cinco princípios de identidade propostos por Reed II et al. (2012). Em seguida, as entrevistas foram transcritas.

Quanto a técnica de análise dos resultados, procedeu-se com a análise de conteúdo qualitativa em grade mista (BARDIN, 2016), seguindo as etapas de pré-análise das entrevistas; de exploração do material; e de inferência, interpretação e tratamento dos resultados. Os princípios de identidade Reed II et al. (2012) foram categorias previamente estabelecidas, de modo que o Quadro 3 ilustra as situações em que as falas dos entrevistados poderiam apontar de traços de saliência, associação, 
relevância, verificação e conflito de identidade. A partir destas categorias foram criadas subcategorias, as quais estão descritas na seção de resultados.

\begin{tabular}{|c|c|}
\hline $\begin{array}{l}\text { Princípio } \\
\text { identitário }\end{array}$ & Aplicabilidade no contexto de consumo de vinhos \\
\hline Saliência & $\begin{array}{l}\text { O consumidor de vinhos afirma veementemente a sua percepção de identidade, em } \\
\text { relação ao consumo da bebida em questão, independente se aprecia o produto em } \\
\text { contextos sociais ou individualmente. Declara que possuí características que o torna } \\
\text { único, se comparado aos demais consumidores de vinhos. Tem interesse pela a opinião } \\
\text { de grupos externos ou de referência, os quais podem moldar suas atitudes, ou reforçar a } \\
\text { sua identidade em face ao consumo de vinhos. }\end{array}$ \\
\hline Associação & $\begin{array}{l}\text { O consumidor de vinhos pode associar lembranças, memórias e informações } \\
\text { importantes para determinar a sua noção de identidade. Tais estímulos positivos, } \\
\text { indicam significados sobre o autoconceito do consumidor. Também considera-se que } \\
\text { pode haver transferência associativa entre os membros de um grupo de consumo da } \\
\text { bebida, ou seja, o indivíduo associa a sua identidade conforme o discurso comum, ligado } \\
\text { ao seu universo de convívio social. }\end{array}$ \\
\hline Relevância & $\begin{array}{l}\text { O consumidor de vinhos expressa a sua relevância identitária, em face a(o): } \\
\text { a) vinho em si, objeto que permeia o contexto de consumo e define a formação } \\
\text { identitária; } \\
\text { b) simbolismo do consumo, em que a posse, crença ou contexto de consumo, indica os } \\
\text { traços identitários do consumidor. Considera-se também, a visão de sua identidade aos } \\
\text { olhos dos outros consumidores, bem como os julgamentos de impressão; } \\
\text { c) objetivo em consumir a bebida, em que a presença em um contexto de consumo, exige } \\
\text { comportamentos apropriados em face à afiliação em um grupo de consumidores. A } \\
\text { adoção de um estilo de vida, e a influência de diferentes tipos do produto, também são } \\
\text { considerados; } \\
\text { d) ação, de acordo com as atitudes ligadas à identidade particular do consumidor de } \\
\text { vinhos, ou ainda, mediante as posses que o capacitem para realizar tais ações; } \\
\text { e) avaliação, em que a identidade consolidada, permite ao consumidor de vinhos avaliar } \\
\text { a especificidade e clareza que as suas posses e comportamentos, desempenham na sua } \\
\text { identidade. }\end{array}$ \\
\hline Verificação & $\begin{array}{l}\text { O consumidor de vinho se importa com a maneira que é visto pelos demais, havendo a } \\
\text { necessidade monitorar a fidelidade de sua identidade, conforme a imagem que quer } \\
\text { passar do seu autoconceito. Então, os comportamentos e atitudes no contexto do } \\
\text { consumo de vinhos, são verificados mediante a sua noção do "eu", visando validar a sua } \\
\text { identidade perante o ambiente que se está inserido. Nas eventuais aspirações por novas } \\
\text { identidades, o consumidor desempenha comportamentos conforme o "eu ideal", } \\
\text { perseguido na identidade pretendida. }\end{array}$ \\
\hline Conflito & $\begin{array}{l}\text { O consumidor de vinho pode apresentar várias identidades ligadas ao seu autoconceito, } \\
\text { o que eventualmente, abre a possibilidade destas identidades entrarem em conflito. } 0 \\
\text { consumidor pode adotar uma postura harmônica, desempenhando comportamentos } \\
\text { consistentes com as múltiplas identidades. A menção de processos autorregulatórios, } \\
\text { caracteriza a tentativa de manter a integralidade entre as identidades conflitantes. Nesse } \\
\text { sentido, o consumidor de vinhos deve monitorar e reduzir o conflito percebido entre } \\
\text { identidades. }\end{array}$ \\
\hline
\end{tabular}

Fonte: Reed II et al. (2012) - adaptado pelos autores

Quadro 3. Princípios de identidade no comportamento de consumo de vinhos

De acordo Reed II et al. (2012), é possível compreender a formação da identidade do consumidor, na perspectiva dos princípios de saliência, associação, relevância, verificação e conflito, os quais podem explicar como as pessoas usam de seus traços identitários mediante a diferentes contextos de consumo. Neste caso, as falas dos entrevistados foram analisadas e descritas conforme os princípios de identidade relacionados na teoria destes autores, porém, em face ao contexto das motivações de consumo de vinhos que permeiam este estudo. 


\section{RESULTADOS E DISCUSSÃO}

Conforme dito anteriormente, durante a leitura das entrevistas julgou-se necessário criar subcategorias correlacionadas aos princípios identitários de Reed II et al. (2012), para viabilizar a análise e interpretação das entrevistas. Logo, considerou-se o contexto do comportamento de consumo de vinhos ligado a realidade dos entrevistados, conforme descritos no Quadro 4.

\begin{tabular}{|c|l|l|}
\hline \multicolumn{2}{|c|}{$\begin{array}{c}\text { Princípio identitário } \\
\text { Saliência }\end{array}$} & $\begin{array}{c}\text { Subcategorias relacionadas aos princípios identitários no contexto de } \\
\text { vinhos }\end{array}$ \\
\hline \multicolumn{2}{|c|}{ Associação } & Memórias e lembranças | Localidades | Atividades | Pessoas \\
\hline \multirow{2}{*}{ Relevância } & Objeto em si & Marcas e vinícolas | Estilo de vinho | Comparação \\
\cline { 2 - 3 } & Simbolismo & Crenças | Significados | Julgamento de impressões \\
\cline { 2 - 3 } & Objetivo & Ter os mesmos gostos | Afiliação \\
\cline { 2 - 3 } & Ação & Beber por beber | Presentear | Redes sociais \\
\cline { 2 - 3 } & Avaliação & Fases da vida | Senso crítico | Julgamentos de atitudes \\
\hline \multirow{2}{*}{ Verificação } & $\begin{array}{l}\text { Cumprir normas | Validar fidelidade | Preço | Mudar ou conservar | "Eu } \\
\text { ideal” }\end{array}$ \\
\hline \multicolumn{2}{|c|}{ Conflito } & Efeito pejorativo | Preferência variada | Não há glamour no vinho \\
\hline
\end{tabular}

Fonte: Dados da pesquisa.

Quadro 4. Princípios identitários e subcategorias de análise no contexto do vinho

As subseções seguintes apresentam os resultados de cada um dos princípios identitários. No decorrer do conteúdo destes resultados, pequenas adaptações no nome das subcategorias podem ocorrer, com o objetivo de melhorar fluência e compreensão do texto. Além disto, nas situações em que a subcategorias de princípios identitários tivessem alguma relação com o que foi abordado em estudos anteriores, com base na revisão de literatura apresentada, resgatou-se os respectivos trabalhos para endossar os traços de identidade que emergiram nas entrevistas.

\section{O princípio de saliência}

Um dos fatores que expressam a saliência identitária do consumidor de vinhos, é a afirmação veemente da sua percepção de identidade. Ou seja, o indivíduo assume (ou não) ter traços, estereótipos ou denominações, que o caracterize enquanto uma pessoa diretamente vinculada com o mundo da vitivinicultura [eu sou uma enófila, o vinho cabe em todos os momentos da minha vida - E. 38]. Eles demonstram interesse no assunto, mas não se dizem tão entendedores, se comparado aos profissionais sommeliers que atuam no mercado [eu não sou sommelier, não sou nada, mas sou visto como o cara que sabe escolher o vinho - E. 06]. Estes vínculos reforçam aos olhos dos outros, a imagem que a pessoa passa enquanto um consumidor da bebida, além de influenciar na socialização com outras pessoas [Sempre que ela ouvir falar, tiver um burburinho a respeito de vinho, ela já vai entrar na conversa - E. 22]. No estudo de Spielmann, Babin e Vergote (2016) a afirmação da identidade também foi abordada mediante o consumo de vinhos. Estes autores complementam que a autoimagem é coerente com os traços identitários que os indivíduos querem afirmar, considerando a dimensão social e o contexto de vida destas pessoas.

0 princípio de saliência, também pode ser explicado diante dos consumidores que assumem características, hábitos ou reconhecimentos que posicionem a sua autoimagem única, diferente ou exclusiva, se comparado aos demais consumidores existentes no ramo da enologia. Alguns dos exemplos, retratam indivíduos que desempenham atitudes durante a degustação que não são feitas por todos [antes eu tomava vinho, hoje eu degusto. Tem gente que pega e vira, poucos são como eu sou hoje - E. 05] ou o fato de se obter destaque e status pela facilidade em se identificar característica do vinho [Não é uma coisa comum extrair todos os aromas numa leitura simples, o que significa um certo status no meio do vinho - E. 22]. 
Por fim, o princípio de saliência em identidade é capaz de moldar ou reforçar atitudes, que o consumidor possa desempenhar para afirmar a noção de quem ele é, em relação ao mundo dos vinhos. Então, o consumidor busca por meios que reforcem suas características identitárias [o meu objetivo agora é começar um curso de sommelier. Para tudo ficar completo - E. 23], ou ainda, se deixe influenciar por grupos sociais de seu relacionamento próximo [uma influência familiar, de amigos, até de uma questão de trabalho, que foi o meu caso - E. 22].

Conforme pode ser visto nesta subseção, o princípio de saliência se faz importante para compreender os consumidores de vinhos que afirmam fortemente a sua identidade. Em seguida, demonstra-se como o princípio de associação contribui para o entendimento dos traços identitários que constroem o perfil de comportamento de consumo dos consumidores de vinhos.

\section{O princípio de associação}

Nas situações em que as memórias e lembranças determinam a percepção identitária do indivíduo, o princípio de associação remete-se aos momentos ou ideias que já foram vivenciados pelo consumidor de vinhos. Neste sentido, estes momentos adquirem significados que viabilizam o resgate de experiências passadas, as quais refletem na noção de identidade que o indivíduo tem de si atualmente. Isto pode promover algumas introspecções sobre a vida do consumidor [existe uma associação de ideias entre o consumo de vinho e o viver. Tudo é uma constante evolução - E. 04], ou ainda, retomar experiências que conectam o consumidor com algum local já visitado anteriormente [vou me lembrar dos momentos que passei por aquele lugar, por aquilo que vi, senti e vivi naquele lugar E. 18].

Outra influência que o princípio de associação exerce na formação de identidade dos consumidores de vinhos, se diz respeito a localidades ao redor do mundo. Nestes casos, a associação identitária por uma região ocorre quando há alguma descendência de um país tradicional na produção de vinhos [eu tenho uma ligação forte com a Itália. Tenho família lá, e a gente toma vinho todos os dias, de diversas vinícolas - E. 20], ou ainda, queira estabelecer um vínculo associativo entre o estilo de vida de uma população com o vinho [a pessoa considera a França um lugar de pessoas eruditas. A boa sensação vem daí, da identidade que você cria com um povo, num modo de vida, com a visão das pessoas do lugar - E. 35].

O princípio de associação também pode ocorrer por transferência associativa do discurso comum, mediante as atividades que estejam ligadas ao seu convívio social. Estas transferências associativas associam o consumo de vinhos com outros hábitos, hobbies, culturas, posses ou produtos, que caracterizem a aproximação de outros grupos e nichos sociais. São exemplos a atividade de leitura [o vinho é o "livro" que eu gostaria de beber. Os melhores momentos da minha vida, seria esse o título - E. 27], e ouvir música [uma música você tem que ouvir mais de uma vez, para se acostumar com o som. Vinho é a mesma coisa, pois você passar a gostar porque entrou em sintonia - E. 21].

Outra forma que também pode-se ocorrer uma transferência associativa, é por meio da comparação com pessoas inseridos na cultura do vinho, que possuem experiências diferentes. 0 princípio de associação neste caso, aplica-se na transferência associativa entre pessoas mais próximas do convívio social do consumidor [todos já moraram na França, para eles é um pouco isto, ah, sou intelectual. Estou bebendo um vinho que estudei em Paris - E. 35], bem como entre profissionais do ramo da viticultura [creio que o enólogo não é muito diferente de mim. Ele vai buscar sempre um bom vinho - E. 34], ou ainda, celebridades que tem apreço e estima declarada pelo consumo de vinhos [o Antônio Fagundes falou que o vinho que o deixou mais deslumbrado na vida foi o Amarone. Pô alguma coisa nós temos em comum - E. 02].

Esta subseção, demonstrou diferentes maneiras em que o princípio de associação pode exercer influência na formação dos traços identitários dos consumidores de vinhos. Em sequência, apresentase o princípio de identidade em comportamento de consumo que considera a relevância de alguns fatores na construção de identidade dos consumidores de vinhos. 


\section{O princípio de relevância}

Quando considerado o objeto em si, ou seja, o vinho enquanto a bebida que permeia o contexto de consumo e define a formação identitária dos consumidores, é relevante apontar que marcas, vinícolas, tipo e estilo de vinho são fatores determinantes. Outro ponto que merece destaque em função do vinho em si na identidade, é a comparação e o posicionamento destes consumidores com quem toma outro tipo de bebida, sendo exemplo cerveja comum e artesanal.

As marcas ou vinícolas são considerados parâmetros para diferenciar os consumidores que buscam por vinhos reconhecidos e consolidados no mercado, em comparação com vinhos de acesso mais difundido entre o público geral. Deste modo, algumas marcas ou vinícolas tem o poder de definir traços identitários dos consumidores, uma vez que influencia na forma de consumo destas pessoas [tem Brunello e Brunello. Tem linha que é uma coisa chique né, difícil a gente ter acesso. Logo, eu não posso abrir um vinho excelente para comer com um Miojo - E. 12]. Quanto ao estilo, o vinho doce é algo para quem não tem costume de degustar vinhos, diferente do vinho seco, em que o consumidor tem que se propor a treinar para conseguir identificar as nuances existentes [o brasileiro está acostumado com o vinho suave e adocicado. $O$ paladar europeu eu tenho porque tive contato com vinhos do mundo inteiro - E. 39]. Em comparação com outras bebidas, é possível dizer que o vinho tem características próprias em decorrência do ritual de consumo, que não é encontrado na cerveja comum [cerveja você chama e bebe com qualquer um. Vinho você seleciona algumas pessoas, é mais intimista - E. 32], embora haja uma ressalva disto quanto as cervejas artesanais [na cerveja artesanal você vai pagar mais caro $e$ espera ter um olfato, um sabor diferenciado para compartilhar - E. 34].

0 princípio de relevância pode ser interpretado pelo simbolismo que o consumo pode ter para o consumidor de vinhos. Neste sentido, as crenças e as atribuições de significados são meios que evidenciam o simbolismo que a bebida exerce para estas pessoas, sendo relevante os julgamentos de impressões por outras pessoas, em detrimento do consumo da bebida.

Quanto a relevância simbólica que as crenças desempenham na formação identitária do consumidor de vinhos, estas podem estarem atreladas a fatores que correspondem a religião, dogmas, historicidade e espiritualidade [somos seres espirituais em uma experiência humana e o objetivo de nossas vidas aqui é a evolução. $O$ vinho de alguma forma ajuda despertar a minha mente - E. 18]. No sentido de atribuição de significados, consiste em relacionar algum aspecto do ritual de consumo do vinho em si, com algum significado simbólico que possa expressar momentos da vida do consumidor, ou ainda, condutas e atitudes que explicam os traços que caracterizam a sua identidade [o harmônico do vinho aí retrata na própria vida mesmo, é o espelho da vida. Você ter harmonização e equilíbrio com as pessoas - E. 26]. A relevância simbólica do vinho pode fazer com que as pessoas realizem julgamentos de impressões, sendo muito comum, o estigma da bebida como pertencente a uma cultura de pessoas elitizadas [no Brasil, o vinho veste terno, tem um Rolex no braço, anda de Mercedes. Para o brasileiro, ele é elitizado. Fui buscar historicamente o porquê deste estigma. Está atrelado a elite portuguesa que colonizou o Brasil. Desde então, ficou taxado como uma bebida para a elite - E. 30]. Em alusão aos achados de Rössel e Pape (2016), os julgamentos de impressões, de fato, podem ter algum respaldo no consumo de vinhos. Estes autores apontam que pessoas com alto padrão social e um estilo de vida elevado, possuem maior engajamento com produtos vitivinícolas, embora os fatores econômicos não sejam determinantes na formação identitária do consumidor.

No que se refere ao princípio de relevância por objetivo, os consumidores de vinhos que possuem os mesmos gostos e preferências desempenham comportamentos apropriados, visando a afiliação e aceitação de um grupo. Também pode ser visto considerando-se um estilo de vida, em razão de um cotidiano atribulado pelas obrigações do trabalho.

Os entrevistados dizem que reunir pessoas que tem os mesmos gostos, é uma forma de empatia que agrega no ritual de consumo de vinhos. Neste sentido, existe uma troca de experiência neste grupo social, de modo que os consumidores de vinhos se sentem à vontade e se identificam com os demais membros [se você tem pessoas afins que gostam de vinho, aquele momento vai trazer descontração a todo mundo - E. 09]. No caso dos consumidores de vinhos, há uma busca em se obter a afiliação e aprovação no meio social. Então, eles objetivam agradar as pessoas, fazer com que elas se sintam acolhidas e engajadas, se demonstrando confiável entre os participantes [numa confraria que já 
tem 10 anos, ela vai começar e se sentir aceita, acolhida - E. 22], de modo a valorizar e retribuir um dia, toda a receptividade que obteve [assim como eu aprecio quando vou na casa de um amigo e sou servido por um bom vinho. É demonstrar o quanto você valoriza e está satisfeito em recebe-la - E. 36]. De acordo com a pesquisa de Roe e Bruwer (2017), a afiliação de uma pessoa em um grupo de consumo de vinhos já estabelecido, cria a necessidade de aprovação social perante aos membros existentes. Além disto, os novos participantes preocupam-se com a percepção que o grupo tem de si, e, em muito dos casos, consomem vinhos mais caros para afirmarem a sua identidade em busca da aprovação social.

Quanto ao princípio de relevância por ações desempenhadas pelos consumidores de vinhos, estas também são meios de se construir a identidade em face ao comportamento de consumo. Algumas das ações relatadas pelos entrevistados, estão relacionadas ao ritual de degustação, ao ato de se presentear pessoas, e o uso de aplicativos de smartphones.

Os consumidores de vinhos não usufruem da bebida unicamente pelo o ato de beber por beber em si, em que a ação de consumo da bebida é proveniente do ritual de degustação, para que se possa experimentar as sensações que o vinho tem a oferecer junto da harmonização de um prato [é uma experiência de sensações, você não toma vinho meramente para matar a sede, ou para ficar bêbado - E. 03]. Presentear pessoas é uma forma de compartilhar uma boa experiência de consumo que foi vivenciada, com uma pessoa que seja estimada e tenha apreço pelo consumidor que pratica o ato, além de ser uma forma disseminar a cultura do vinho para mais pessoas [quando você compartilha $e$ a pessoa aceita, o vinho é um presente. Você está disseminando o prazer que você tem - E. 38]. Já o uso das redes sociais, consiste em uma ação de busca por vários tipos informações relacionadas ao mundo dos vinhos, bem como a expressão das opiniões e avaliações do consumidor sobre a bebida que foi experimentada [uso o aplicativo da Vivino. As pessoas se sentem bem colocando avaliações lá - E. 07]. No trabalho de Higgins e Wolf (2016), as redes sociais e plataformas digitais também foram apontadas como meio de troca de experiências e informações sobre o vinho, sendo um meio contato com o mundo dos vinhos.

O último fator que está incluído no princípio de relevância, é a avaliação da identidade consolidada do consumidor de vinhos, que permite checar a especificidade e clareza que os seus comportamentos ou posses, desempenham na construção de sua identidade. Neste sentido, algumas destas avaliações estão correlacionadas ao sentimento de se ficar mais exigente com o passar do tempo, de se questionar a opinião de pessoas atuantes e especializadas no ramo da enologia, e de cumprir com o que se é esperado no ritual de consumo.

Os entrevistados afirmaram que há uma evolução em quem consome vinhos de forma assídua, conforme as fases da vida do consumidor. Eles avaliam que com o passar do tempo, há uma tendência de o consumidor ficar mais exigente com relação a bebida, buscando aspectos que tragam mais satisfação do ponto de vista das experiências do consumo [eu já tomei vinhos mais simples. Depois você começa a ficar mais seletivo, do ponto de vista de satisfação - E. 08]. Então, há o desenvolvimento de um senso crítico que permite avaliar a opinião e julgamentos de pessoas especializadas no mundo dos vinhos, tais como sommeliers e influencers, uma vez que o consumidor de vinhos tem conhecimento ou experiência suficiente para se questionar as informações que são veiculadas como verdadeiras entre os profissionais do vinho [quando você estuda mesmo nos livros e os viticultores te ensinam as coisas, você vê como as pessoas repetem bobagens e coisas erradas - E. 20]. Outra forma de avaliação é o julgamento de atitudes, que podem ser consideradas inadequadas entre os consumidores de vinhos, tais como beber apenas para se alterar o estado de consciência, ou ainda, não utilizar das técnicas de degustação como deveria [tem muita gente que aprende a técnica e esquece o que está fazendo, ou vai pelo o que os outros conduzem na degustação - E. 15].

Diante do exposto, foi possível entender como o princípio de relevância se aplica na formação identitária dos consumidores de vinhos, por meio do objeto em si, do simbolismo do consumo, do objetivo em se consumir, das ações e atitudes, e dos meios de avaliar a identidade. A próxima subseção apresenta a identidade sob a ótica do princípio de verificação. 


\section{O princípio de verificação}

Uma das formas de se monitorar os comportamentos desempenhados pelos indivíduos no contexto de consumo de vinhos, considerando o princípio de verificação de sua identidade, é pelo cumprimento de normas e costumes implícitos, que podem caracterizar um grupo de consumo. Neste sentido, grupos de consumidores de vinhos podem seguir algumas etiquetas, que regem os rituais sociais de consumo. No entanto, o cumprimento destas normas e costumes, pode ser um fator positivo, quando relacionada a se preservar a união e estabilidade de um grupo; ou negativa, quando as regras tornam-se um empecilho moroso, que resulta no desmanche e perda de interesse pela participação do indivíduo no grupo. Dado a necessidade de entender o contexto de consumo em que ocorrem tais situações, é necessário apresentar dois trechos (quase na integra) para ilustrar o princípio de verificação no cumprimento de normas:

Nós temos um grupo de estudo que começou com uma confraria formada por 12 pessoas. Aí, este grupo foi tomando uma forma de trabalho que ficou cansativo [...] e começou em vez de ser uma confraria de prazer, começou a ser uma coisa muito trabalhosa e que despendia de muito tempo de dedicação aquilo. Aí algumas pessoas foram saindo, e quando restou 5 pessoas a gente falou assim, olha gente o que que aconteceu com o nosso grupo de estudos? Fizemos uma introspecção dentro dele, e descobrimos que estava cansativo, chegamos a uma conclusão que era pesado demais e a gente seguia muito as regras [...] e qual que é o intuito que virou o grupo, nós vamos nos encontrar para beber vinho, mas ninguém fala de vinho. Viramos literalmente uma roda de amigos que começou com uma coisa chata - E. 19.

A etiqueta no consumo de vinho é muito parecida com a etiqueta em forma geral de se comportar quando você recebe ou vai à casa de alguém. Digamos rituais sociais que regem o comportamento das pessoas em situações bastante específicas. Você vai evitar constranger um anfitrião, fazendo comentários negativos sobre algo que foi servido [...] mas se eu for na casa de uma pessoa com a qual eu não tenho tanta intimidade assim, a pessoa me serviu um vinho que inclusive já estava avinagrado, eu fiquei quieto, a gente toma um pouquinho ali, e a coisa passa. Se eu faço um comentário ali aconteceria no mínimo um constrangimento - E. 39.

O princípio de verificação de identidade, também aplica-se a algumas atitudes que validam a fidelidade do consumidor de vinhos, considerando o que se espera que seja feito durante a degustação da bebida. Então, mesmo quando uma pessoa que não tenha afinidade com o mundo dos vinhos, julgue e faça objeções às atitudes que são desempenhadas no ritual de consumo classificandoas como uma "frescura" [meu primo toma vinho por tomar. Falei com ele sobre um treinamento de paladar, e ele falou que aquilo era frescura. Eu não quis nem discutir - E. 12], o consumidor de vinhos se mantém fiel e valida a sua identidade [o meu irmão me diz: mas você fica meia hora pra isso? Fica aí girando vinho, pra que isso? - E. 02]

Considerando que o vinho é percebido pelos consumidores brasileiros uma bebida de preço elevado, é natural que o princípio de verificação também possa ser interpretado sob esta perspectiva. A verificação da identidade considerando sensibilidade ao preço, pode ter diferentes significados conforme a imagem que se queira passar. Quando o vinho tem um preço elevado, isto pode ser um entrave que obrigue o consumidor a verificar a sua identidade e tomar uma decisão em comprá-lo (ou não), sobretudo, quando se está na companhia de outras pessoas [as vezes eu quero tomar um vinho um pouco melhor, e tem três casais na mesa, se eu falar que vou tomar o vinho caro, eles podem assustar - E. 02]. Neste aspecto, Ritchie (2007) identificou em seu estudo que a atividade social, seja ela pública ou privada, pode influenciar na decisão do consumidor sobre qual vinho será comprado. Outro ponto importante, é que há um limite de preço que os consumidores consideram investir na bebida, em que o pensamento de se economizar leva ao monitoramento da identidade [apesar de gostar de muitos vinhos exclusivos, eu tenho um limite de gasto dentro da minha capacidade de pagamento - E. 14]. Conforme o estudo conduzido por Higgins e Wolf (2016), a renda financeira também foi considerada 
um fator relevante na formação de identidade do consumidor de vinhos, havendo um paralelo entre o valor monetário investido na compra da bebida e verificação identitária.

Outra maneira de se monitorar e validar um traço identitário, de acordo com o princípio de verificação de identidade, é a predisposição em se mudar ou conservar hábitos de consumo. 0 consumidor de vinhos verifica a fidelidade na identidade que transmite, quando são colocadas possibilidades antagônicas do consumo. Ou seja, nas situações em que o indivíduo valorize por sempre experimentar novos vinhos, ele reforça que não gostaria de ficar preso a apenas uma única variedade da bebida [você gosta tanto deste vinho, vou te fazer uma proposta. A partir de hoje você só vai beber deste vinho, você quer? Não, ninguém quer - E. 21]. Quando a pessoa adota uma postura conservadora, ela valida a sua identidade ao preferir algo que já é conhecido [sou mais conservador, a ideia de não arriscar. Prazeres já desfrutados se repete - E. 36]. No caso dos consumidores conservadores, o estudo de Bruwer e Li (2007) caracterizou este grupo de pessoas mediante o hábito de beber vinhos finos com frequência, sendo fatores importantes aqueles relacionados a procedência, ocasião de consumo e canal de compra da bebida.

Finalmente, os indivíduos podem aspirar por novas identidades em um grupo de consumo, e em função disto, faz-se necessário desempenhar comportamentos em busca deste "eu ideal". Neste sentido, o princípio de verificação de identidade é um meio de se monitorar algumas destas ações, que permitem que o consumidor faça parte de um grupo social [é querer ir atrás do grupo e isto realmente exige bastante prática. Vai ter que tomar vinho várias vezes, para captar o entendimento do grupo - E. 22]. Tais atitudes em busca da afiliação podem melhorar a autoestima, mas requer dedicação e prática do consumidor [quando eu consigo cozinhar e harmonizar, e as pessoas falam que ficou legal, aquilo pra mim é o ápice - E. 06].

De acordo com o que se foi exposto, o princípio de verificação é um importante meio para o consumidor de vinhos monitorar e validar sua noção identitária, ou ainda, aspirar por novas identidades. Em seguida, apresenta-se de que maneira o princípio de conflito de identidade, pode ser útil para se descrever os traços identitários dos consumidores de vinhos.

\section{O princípio de conflito}

Um conflito de identidade que permeia o contexto do mundo do vinho, é a existência de traços identitários que designam perfis de consumidores que não sejam habituais, como enófilos ou sommeliers, o que gera um efeito pejorativo e conflitante sob a identidade do autêntico consumidor de vinhos. 0 primeiro identificado foi o "bebedor de rótulo", ou seja, aquele indivíduo que apenas segue algumas indicações, e na maioria das vezes se decepciona, por não deter do conhecimento necessário para se fazer uma compra acertada [o fulano fala que o vinho é bom, compra e leva pra casa. Chega lá e se decepciona. São chamados os bebedores de rótulo - E. 08]. 0 segundo perfil trata-se dos "enochatos", que são as pessoas que "acham que sabem demais" e tem a necessidade de fazer comentários sobre a bebida, em situações que não haveria motivo para tal comportamento [existem os enochatos. São pessoas que não entendem nada de vinho e querem falar das características da bebida num contexto que não tem porque - E. 30].

Diante da existência de consumidores com traços identitários pejorativos, ou seja, os bebedores de rótulo e os enochatos, os consumidores adotam processos autorregulatórios para manter uma postura harmônica com estas pessoas. De certa forma, esta atitude evita processos conflitantes entre as diferentes identidades que se fazem presentes em um grupo de consumo [como que você vai tomar um vinho com quem você não gosta? Você até toma por obrigação, mas não é um prazer - E. 16], promovendo comportamentos consistentes para monitorar e reduzir o conflito percebido entre os membros do grupo de consumo [já tomei vinhos modestos com pessoas maravilhosas, que realmente melhorou a bebida. Mas se vier uma pessoa azeda, atrapalha o vinho também. Toma vinho com uma pessoa chata que você vai entender - E. 21].

Entre os consumidores de vinhos, existem algumas particularidades com relação ao gosto por um determinado estilo da bebida. Esta realidade pode gerar conflitos entre as identidades destas pessoas, em detrimento das preferências variadas de consumo. Neste sentido, o princípio de conflito pode desempenhar um processo autorregulatório nos traços identitários do consumidor, fazendo com 
que ele adote uma postura harmônica e abra a mão de suas preferencias [eu e minha esposa estamos ali para descontrair. A gente vai brigar por causa do vinho, porque eu quero aquele e ela quer o outro? - E. 11], em respeito ou por falta de opção pelo gosto de uma outra pessoa [em casa, a gente bebe aquilo que agrada. Num ambiente com mais pessoas, você não tem o direito de escolher e vai na média dos que estão lá - E. 05].

Por fim, uma outra questão que emergiu no discurso dos entrevistados, é o fato do vinho ter o estigma de ser taxada como uma bebida glamorosa e burocrática. De alguma forma, isto representa um conflito de identidade para alguns dos consumidores de vinhos, que afirmam não haver a necessidade deste estigma que existe em torno da bebida [o vinho não é pra ser glamour. A gente acha que tem que tomar vinho em uma taça de cristal. Você pode tomar em um copo de requeijão, não existe essa glamorização que tem se feito com o vinho - E. 30]. Eles atribuem que a maior acessibilidade e a informalidade seriam um meio autorregulatório para romper este conflito [está cada vez mais em um contexto informal, sem haver a necessidade de celebrações muito especiais como no Brasil. Em outros países o vinho é menos burocrático - E. 20]. Retomando o estudo de Bruwer e Li (2007), é possível inferir que os consumidores que detém esta visão não glamorosa da bebida, possam se enquadrar nos traços identitários do grupo de "bebedores básicos", os quais não prezam por rituais de consumo ou outras exigências em relação ao produto. Além disto, Rössel e Pape (2016) mencionaram que a maior democratização relativa ao acesso e a variedade existente da bebida, faz com que muitos consumidores esporádicos não desenvolvam traços identitários mediante ao consumo de vinhos.

0 princípio de conflito de identidade em comportamento de consumo, é um meio de se manter a harmonia entre as várias identidades que podem estar presentes em um contexto social. Então, os processos autorregulatórios se fazem necessários para que se atinja a estabilidade entre as identidades conflitantes, conforme foi descrito nesta subseção.

\section{CONSIDERAÇÕES FINAIS}

Após analisar os princípios de saliência, associação, relevância, verificação e conflito (Reed II et al., 2012), afirma-se a pertinência destes traços identitários para descrever os aspectos que constroem a identidade dos consumidores de vinhos, baseados nas motivações que guiam o seu comportamento de consumo. Neste sentido, é possível tecer alguns comentários a respeito da identidade dos consumidores de vinhos entrevistados.

Considerando o princípio de saliência, percebe-se que existe uma afirmação identitária por parte destas pessoas, uma vez que elas expressam veementemente serem participantes de um meio social em que o vinho se faz presente. Então, a saliência de identidade ocorre quando há uma afirmação de quem o consumidor é, sendo um exemplo utilizado, o fato destes indivíduos se considerarem um enófilo, um apaixonado por vinhos. Além disto, eles buscam moldar ou reforçar a sua identidade, buscando por características que os tornem únicos no meio.

No que se refere ao princípio de associação, a identidade do consumidor de vinhos é relacionada a memórias e lembranças importantes em que o vinho esteve presente, ou ainda, localidades que tenham visitado, criando um vínculo com os conterrâneos. Estas pessoas também afirmam que há uma associação de identidade com demais pessoas ou atividades de recreação que caracterizem um grupo de consumo, ocorrendo uma transferência associativa.

Em termos dos aspectos que compõem o princípio de relevância, o vinho enquanto o objeto em si que permeia o contexto de consumo, pode ser uma forma de guiar um traço identitário, diante de marcas, vinícolas ou estilos de vinhos, bem como criar uma distinção de outras bebidas, tal como a cerveja comum e artesanal. 0 simbolismo também se faz relevante na formação de identidade, pois há consumidores que atribuem crenças e significados a bebida, bem como desenvolvem a capacidade de fazer julgamentos de impressão. 0 objetivo do consumo demonstra a sua relevância, quando um meio social possui o mesmo gosto por vinho, o que facilita a afiliação da identidade. Já a relevância da ação, esta permite que o consumidor desempenhe atitudes correspondentes a identidade, por meio de rituais de consumo, presentear pessoas e participar de redes sociais. Por fim, o princípio de relevância por avaliação é uma maneira do consumidor desenvolver um senso crítico, a medida em que adquira experiência durante as fases de sua vida, o que permite fazer julgamentos de atitudes. 
No que tange ao princípio de verificação, os consumidores de vinhos monitoram os seus comportamentos quando cumprem (ou não) normas e condutas, visando validar a fidelidade de sua identidade. Outros meios de se verificar os traços identitários, é quando um preço de um vinho está acima de um limite estabelecido, o que faz pensar se vale a pena compra-lo ou não; nas situações em que a mudança ou a manutenção do seu comportamento é uma forma de testar e verificar a fidelidade de sua identidade; e ainda, quando o consumidor aspira por uma nova identidade em busca do "eu ideal", o que o faz desempenhar comportamentos não habituais.

Por fim, o princípio de conflito identitário ocorre quando múltiplas identidades presentes em um contexto de consumo, faz com que os consumidores tenham que desempenhar comportamentos autorregulatórios, para estabelecer a harmonia no ambiente de convívio. Neste contexto, estão inseridos os "enochatos" e "bebedores de rótulo"; os consumidores que tem preferencias distintas entre vinhos, o que leva a pessoa abrir mão de seu gosto particular; e os que defendem que o vinho não deve ser glamour, contrapondo o estigma atribuído a bebida.

Mediante as informações obtidas nesta pesquisa, algumas implicações podem ser discutidas. No âmbito das implicações teóricas, acerca da proposição feita por Reed II et al. (2012) sobre o estudo da identidade em comportamento de consumo, este artigo reafirma a pertinência em se utilizar desta perspectiva teórica, para se compreender os traços identitários que constroem a autoimagem no consumo. Deste modo, evidencia-se que a motivação atrelada ao consumo, pode exercer grande influência sobre os traços identitários que compõem a noção de que o consumidor tem de si, sobretudo, no mundo contemporâneo em que as identidades são maleáveis, instáveis, mutáveis, fragmentadas e líquidas (Bauman, 2005).

Quanto as implicações gerenciais, os traços identitários também podem auxiliar na criação de estratégias de comunicação e criação de peças publicitárias. Cada um dos princípios de identidade que foram expostos neste artigo, apresentam várias possibilidades de direcionar uma mensagem que represente a noção que o consumidor tenha de si. Quando deseja-se afirmar o perfil de consumo, a saliência identitária pode ser trabalhada em situações que o indivíduo se sinta único e especial, diante de suas habilidades ou características que são reforçadas ou moldadas em torno de um ambiente social. A associação da identidade também é uma estratégia efetiva no contexto de consumo de vinhos, podendo relacionar-se a outras pessoas, localidades, memorias, grupos ou atividades recreativas de consumo.

Ainda no contexto das implicações gerenciais, quanto a criação de pelas publicitárias e estratégias de comunicação direcionadas aos consumidores de vinhos, também pode-se evidenciar a relevância que o vinho em si pode ter no contexto simbólico, conforme o objetivo do consumo, em que as ações realizadas possam ser avaliadas pelo consumidor. Uma comunicação que vise a verificação de identidade, pode ser uma estratégia benéfica para fazer com que os consumidores de vinhos reflitam a validade de suas ações, sobretudo, quando deseja afiliar-se e obter a aprovação de um grupo de consumo. Considerando o conflito entre identidades, deve-se criar estratégias de comunicação que levem a uma introspecção do consumidor, sobre a necessidade de se ter um convívio harmônico entre os membros de um grupo, sobretudo, quando haja identidades múltiplas, distintas e peculiares.

Conhecer os aspectos que ajudam a construir a identidade dos consumidores de vinhos é fundamental para que se possa aumentar a disseminação da cultura do consumo da bebida no Brasil. Embora o estudo tenha sido delimitado e conduzido em quatro cidades de Minas Gerais, acredita-se que as informações obtidas ofereçam um caminho para atingir este ideal. Sugere-se enquanto agenda de pesquisas, estudos acerca da identidade dos consumidores de vinhos em outros estados do Brasil, para complementar e comparar as informações obtidas neste trabalho.

\section{Agradecimentos}

Fundação de Amparo à Pesquisa do Estado de Minas Gerais 


\section{Referências}

Banks, G., \& Overton, J. (2010). Old World, New World, Third World? Reconceptualising the Worlds of Wine. Journal of Wine Research, 21(1), 57-75.

Barbosa, L., \& Campbell, C. (org). (2006). Cultura, consumo e identidade. Rio de Janeiro: FGV.

Bardin, L. (2016). Análise de conteúdo. São Paulo: Edições 70.

Bauman, Z. (2005). Identidade: entrevista a Benedetto Vecchi. Trad. Carlos Alberto Medeiros. Rio de Janeiro: Jorge Zahar Ed.

Belk, R. (2014). Digital consumption and the extended self. Journal of Marketing Management, 30(11), 1101-1118.

Berríos, R., \& Saens, R. (2015). The country-brand in the wine industry: how important is variety specialization? Academia Revista Latinoamericana de Administración, 28(4), 484-501.

Bruwer, J., \& Li, E. (2007). Wine-Related Lifestyle (WRL) Market Segmentation: Demographic and Behavioural Factors. Journal of Wine Research, 18(1), 19-34.

Bruwer, J., \& McCutcheon, E. (2017). Marketing implications from a behaviourism perspective of consumption dynamics and socio-demographics of wine consumers. Asia Pacific Journal of Marketing and Logistics, 29(3), 519-537.

Carvalho, C. (2016). Anuário brasileiro da uva 2016. Santa Cruz do Sul: Gazeta Santa Cruz.

Clair, J. K. S. (2018). A Beautiful MIN (D): The Multiple-Identity Network as a Framework for Integrating Identity-Based Consumer Behavior. ACR North America Advances. 386-390.

Dubar, C. (2012). A construção de si pela atividade de trabalho: a socialização da profissional. Cadernos Ebape.BR, 42(116), 351-367.

Hall, S. (2006). A identidade cultural na pós-modernidade. Tupy Kurumin.

Higgins, L., \& Wolf, M. M. (2016). Millennials as luxury wine buyers in the United States? International Journal of Wine Business Research, 28(3), 190-205.

Instituto Brasileiro do Vinho. (2018). Panorama geral. Disponível em: <http://www.ibravin.org.br/Panorama-Geral> Acesso em 08 mai. 2020.

Kassarjian, H. H. (1971). Personality and consumer behavior: a review. Journal of Marketing Research, $8(4), 409-418$.

Mello, L. M. R. (2017). Informe técnico: panorama da produção de uvas e vinhos no Brasil. Campos \& Negócios. Uberlândia: AgroComunicação, 54-56.

Oyserman, D. (2009). Identity-based motivation: implications for action-readiness, proceduralreadiness, and consumer behavior. Journal of Consumer Psychology, 19(3), 250-260.

Oyserman, D., Elmore, K., \& Smith, G. (2012). Self, self-concept, and identity. In: M. Leary \& J. Tangney (Eds.), Handbook of self and identity (2. ed.). New York: Guilford, 69-104.

Protas, J. F. S., \& Camargo, U. A. (2011). Vitivinicultura brasileira: panorama setorial de 2010. Brasília: SEBRAE; Bento Gonçalves IBRAVIN - Instituto Brasileiro do Vinho: Embrapa Uva e Vinho. 110 p.

Reed II, A., Forehand, M. R., Puntoni, S., \& Warlop, L. (2012). Identity-based consumer behavior. International Journal of Research in Marketing, 29(4), 310-321.

Ritchie, C. (2007). Beyond drinking: the role of wine in the life of the UK consumer. International Journal of Consumer Studies, 31, 534-540.

Roe, D., \& Bruwer, J. (2017). Self-concept, product involvement and consumption occasions: exploring fine wine consumer behaviour. British Food Journal, 119(6), 1362-1377.

Rössel, J., \& Pape, S. (2016). Who has a wine-identity? Consumption practices between distinction and democratization. Journal of Consumer Culture, 16(2), 614-632.

Souza, M. M. P., \& Carrieri, A. P. (2012). Identidades, práticas discursivas e os estudos organizacionais: proposta teórico-metodológica. Cadernos Ebape.BR, 10(1), 40-64.

Spielmann, N., Babin, B. J., \& Verghote, C. (2016). A personality-based measure of the wine consumption experience for millennial consumers. International Journal of Wine Business Research, 28(3), 228-245.

Stewart, C. \& Cash Jr., W. (2015). Técnicas de entrevista - estruturação e dinâmica para entrevistados e entrevistadores. Porto Alegre: AMGH. 
Udall, A. M., Groot, J. I. M., Jong, S. B. \& Shankar, A. (2020) How do I see myself? A systematic review of identities in pro-environmental behaviour research. Journal of Consumer Behavior, 19(2), 108141. 